Bangladesh J. Bot. 50(3): 939-945, 2021 (September) SpecialＤOI: https://doi.org/10.3329/bjb.v50i5.56448

\title{
EFFECTS OF REDUCED APPLICATION OF SPECIAL ORGANIC FERTILIZERS ON TEA PRODUCTION
}

\author{
Jinbao LiU ${ }^{1,3}$, Minghui Jin* and Zhongan Mao \\ Shaanxi Provincial Land Engineering Construction Group Co. Ltd., \\ Xi'an, Shaanxi, 710075, China
}

Keywords: Special fertilizer, Xinyang tea, Organic fertilizer, Yield, Economic benefit

\begin{abstract}
A trial of special fertilizer reduction and combined application of organic fertilizer on tea production, nutrients and economic benefits was carried out in the tea garden at Shihe Port, Xinyang, Henan Province, China. The experiment has six treatments of customary fertilization (CK), 100\% special fertilizer for tea (T1), nitrogen reduction $20 \%$ (T2), 40\% (T3), 60\% (T4) and 100\% (T5), and special fertilizers at the same time. Among the special fertilizer treatments for tea plants, the germination density, 100-bud weight, fresh tea yield, N, P, and K content of new shoots and economic benefits were the highest in T1 treatment, Results showed that the yield range of the five treatments was $460 \sim 632.4 \mathrm{~kg} \mathrm{hm}{ }^{2}$. Compared with $\mathrm{CK}$, the yield increase rates were $6.11,1.99,-4.21,-13.76$ and $-22.82 \%$, respectively. The growth rates of barber bud density and 100-bud weight were $-20.00 \sim 25.83$ and 8.40 $8.40 \%$, respectively. The content of nitrogen, phosphorus and potassium in the new shoots varied by $0.623 \sim 1.070,0.047 \sim 0.183$ and $1.380 \sim 2.237 \%$, respectively. Therefore, the special fertilizer for tea plants can reduce the nitrogen by $20 \%$ to save costs and increase efficiency.
\end{abstract}

\section{Introduction}

Tea trees are perennial cash crops and picked many times a year (Costa et al. 2007). Fertilization is one of the important means to increase the nutrient supply of the tea trees from the soil, ensure the normal growth of the tea trees, and improve the yield and quality of tea (Sun et al. 2016). The contribution rate of fertilizer input to the increase tea production is as high as $41 \%$, which exceeds the contribution rate of land (25\%) and labor (8\%) (Bora et al. 2019, Shen et al. 1990). With the expansion of the area of tea gardens, some tea farmers have used a large amount of chemical fertilizers in pursuit of economic benefits resulting imbalances in the structure of tea garden fertilizers, imbalances in nutrient ratios, decline in tea quality, increased production costs, reduced soil organic matter content, soil acidification compaction, water pollution, etc. (Maltas et al. 2013). Zwa et al. (2019) and Maghanga et al. (2013) reported that it is consistent with habitual fertilization, through a reasonable proportion of nitrogen, phosphorus and potassium, and the appropriate addition of organic matter and trace elements, which not only effectively increase the weight of buds and leaves, increase the yield, but also improve the quality of crops. Simultaneously, the application of special fertilizer for tea trees increased the yield of fresh leaves by an average of $2.5 \mathrm{~kg} / \mathrm{hm}^{2}$ and the output value by $24.5 \mathrm{yuan} / \mathrm{hm}^{2}$ ( $\mathrm{Ji}$ et al. 2018). Compared with the blank, the output-to-input ratio could reach 1:7.67 (Ruan et al. 2004). The increased application of organic fertilizers in tea gardens can increase soil carbon content and nutrient content, improve soil humification and increase its activity, and at the same time can promote tea tree growth and improve the quality of fresh leaves. The combined application of chemical fertilizers and organic fertilizers has more obvious effects ( $\mathrm{Gu}$ et al. 2019, Xie et al. 2020). Because of its unique geographical location, good ecological environment and suitable climate

*Author for correspondence: <jinmh2016@xyafu.edu.cn>. ${ }^{1}$ Institute of Shaanxi Land Engineering and Technology Co. Ltd., Xi' an, China. ${ }^{2}$ Xinyang Agriculture and Forestry University, Xinyang, China. ${ }^{3}$ Shaanxi Provincial Land Consolidation Engineering Technology Research Center, Xi' an, China. 
conditions, Xinyang Maojian has become a famous and special product in Henan Province. At present, the research on Xinyang Maojian tea leaves mainly focuses on the soil environment (Yatoo et al. 2021), quality components, microbial community (Zhang et al. 2020) etc., and the reduction of special fertilizer for tea trees and the combined application of organic fertilizers affect Xinyang tea leaves. There are few reports on the impact of yield and nutrients.

The present study is based on the "excessive application of nitrogen fertilizer, single compound fertilizer ratio, chaotic ratio of chemical fertilizers and organic fertilizers, and small application area of special fertilizers" in Xinyang tea fertilization. Thus this study was aimed to analyze the effects of the appropriate amount of special fertilizer for tea plants and the combined application of organic fertilizers on the tea quantity, nutrient utilization and absorption and economic benefits, and initially integrated the technology model of reducing application and increasing efficiency of special fertilizer for tea plants in Xinyang tea garden. These findings would provide a theoretical reference for the healthy and green development of Xinyang tea gardens.

\section{Materials and Methods}

The experimental site of this research is located at Xinyang Chadu Tea Co., Ltd., Shihegang, Xinyang City, Henan Province, China. It has a northern subtropical monsoon continental climate with an annual average temperature of $15.2 \sim 15.5^{\circ} \mathrm{C}, \geq 10^{\circ} \mathrm{C}$, active accumulated temperature $4900 \sim 5200^{\circ} \mathrm{C} / \mathrm{d}$, annual rainfall $900 \sim 1500 \mathrm{~mm}$, the average annual relative humidity is $77 \%$, the annual sunshine hours are $1904 \sim 2180 \mathrm{hrs}$, the total annual solar radiation is $4700 \sim 5100 \mathrm{MJ} / \mathrm{m}^{2}$, and the frost-free period is $220 \sim 245 \mathrm{~d}$. The soil is yellow brown soil (Sun et al. 2009).

The tea tree variety is Fuding Dabai Tea, all of which are more than 10 years old. The test fertilizer is a special fertilizer for tea trees, with total nutrients of $38 \%\left(\mathrm{~N}-\mathrm{P}_{2} \mathrm{O}_{5}-\mathrm{K}_{2} \mathrm{O}\right.$ is $\left.18-8-12\right)$, adding $6 \%$ of trace elements such as magnesium, zinc, and boron; organic fertilizer organic matter $\geq 45 \%, \mathrm{~N}+\mathrm{P}_{2} \mathrm{O}_{5}+\mathrm{K}_{2} \mathrm{O} \geq 6 \%, 45 \%$ (14-16-15) potassium sulfate compound fertilizer.

The experiment was conducted from October 2016 to May 2017. A total of 6 treatments were set up with an area of $1334 \mathrm{~m}^{2}$ (Table 1). The plots were separated by field ridges to prevent the occurrence of stringing water and fertilizer in each plot. The conventional nitrogen application rate was $315 \mathrm{~kg} / \mathrm{hm}^{2}$ as the target (Hong et al. 2018), and the amount was reduced by 20, 40, 60, and $100 \%$ in sequence, and the same amount of organic fertilizer was applied. The conventional fertilization was used as the control (CK). Fertilizers in each community were applied as a base fertilizer at one time on January 12, 2016. In order to facilitate data collection, $30 \mathrm{~m}^{2}$ of each treatment area was randomly selected as a small area, and 3 repetitions were set up and arranged according to random block groups.

Table 1. Experimental design for fertilizers.

\begin{tabular}{llcc}
\hline Treatment & Type of fertilizer & $\begin{array}{c}\text { Application amount } \\
/\left(\mathrm{kg} / \mathrm{hm}^{2}\right)\end{array}$ & $\begin{array}{c}\text { Nitrogen } \\
\text { reduction ratio }\end{array}$ \\
\hline CK & Potassium sulfate compound fertilizer & 2250 & - \\
T1 & Special fertilizer for tea tree & 1750 & $0 \%$ \\
T2 & Special fertilizer for tea tree + organic fertilizer & 1400,1200 & $20 \%$ \\
T3 & Special fertilizer for tea tree + organic fertilizer & 1050,1200 & $40 \%$ \\
T4 & Special fertilizer for tea tree + organic fertilizer & 700,1200 & $60 \%$ \\
T5 & organic fertilizer & 1200 & $100 \%$ \\
\hline
\end{tabular}


During the spring tea in 2017 , the germination density of each treatment was investigated. When the 1 bud and 2 leaf stage was passed, 5 spots were randomly selected from each plot, and the number of bud tips per spot $(0.3 \mathrm{~m} \times 0.3 \mathrm{~m})$ was investigated, and 1001 buds were randomly sampled 1 leaf new shoot, weight, and the average value of more than three times is the hundred shoots weight of the new shoot. After all the plots were picked, they were individually weighed and calculated.

After the sample was dried and crushed, accurately $0.2000 \mathrm{~g}$ were weighed with a one-tenth electronic balance and was digested with $\mathrm{H}_{2} \mathrm{SO}_{4}-\mathrm{H}_{2} \mathrm{O}_{2}$ until it was clear. Kjeldahl method, molybdenum antimony colorimetric method and flame spectrophotometer were used to determine total nitrogen, total phosphorus and total potassium content, respectively the contents of N, P and $\mathrm{K}$ in this article refer to the total nitrogen, total phosphorus and total potassium content of one bud and one leaf of the tea plant (Bao 2000).

The SPAD value was measured using the chlorophyll content analyzer SPAD-502. When measuring the SPAD value, it is required to avoid the leaf veins and measure the upper, middle and lower parts of the leaf once, and calculate the average value.

Fertilizer input was calculated according to the actual fertilizer price per $667 / \mathrm{m} 2$; tea income was calculated according to the price of fresh leaf output. Net income was calculated according to tea income-fertilizer input.

Statistical analysis used SPSS20 and Excel2010 software for analysis.

\section{Results and Discussion}

The germination density, 100-bud weight, and fresh tea yield range were 64-100 pieces $/ 0.09 \mathrm{~m} 2,10.9-12.9 \mathrm{~g}$, and $632-460 \mathrm{~kg} / \mathrm{hm}^{2}$, respectively (Table 2). Among the six treatments, T1 (100\% special fertilizer for tea plants) treatment had the highest germination density, 100-bud weight and fresh tea yield, followed by T2 (20\% nitrogen reduction), and T5 (100\% organic fertilizer) was the smallest; T1, T2 treatments germinated compared with $\mathrm{CK}$, the density increased by 25.83 and $3.75 \%$, respectively; the growth rate of germination density of T3 (reduced nitrogen by $40 \%$ ), T4 (reduced by $60 \%$ ) and T5 was lower than that of CK. Compared with CK, $\mathrm{T} 1$ and $\mathrm{T} 2$ increased production by 6.11 and $1.99 \%$, and $\mathrm{T} 3, \mathrm{~T} 4$, and $\mathrm{T} 5$ decreased production by $4.21,13.76$ and $22.82 \%$ compared with CK. The analysis of variance showed that the germination density and fresh tea yield were not significantly different from CK when the nitrogen reduction was less than 50\%, and the difference was significant compared with CK. When the nitrogen reduction was higher than $50 \%$, the 100-bud weight changes in different treatments did not show regularity. The difference between the treatments was not significant.

The determination results of the main mineral elements content of mature leaves showed that different treatments have a certain effect on the content of nitrogen, phosphorus and potassium in mature leaves (Table 3). Fertilization treatments T1, T2 new shoots nitrogen uptake was higher than $\mathrm{CK}$, but the difference is not significant, T3, T4, T5 treatments were significantly different compared with CK; T1, T2 treatments new shoots phosphorus uptake was significantly higher than CK, T3, T4, Except for the significant difference between T5 and CK, the other differences were not obvious between T5 treatments. Compared with CK, the potassium uptake of the new shoots of T1 treatment was significantly different, and the other treatments were not significant compared with CK. When a certain amount of organic fertilizer was applied, the appropriate amount of special fertilizer for tea plants has a better absorption effect on nitrogen, phosphorus and potassium compared with conventional treatment. 
Table 2. Effects of different Fertilization treatment on tea yield.

\begin{tabular}{lccccccc}
\hline $\begin{array}{l}\text { Treat- } \\
\text { ment }\end{array}$ & $\begin{array}{c}\text { Germination } \\
\text { density/ } \\
(\text { Pieces/ } \\
\left.0.09 \mathrm{~m}^{2}\right)\end{array}$ & $\begin{array}{c}\text { Growth rate } \\
\text { compared } \\
\text { with CK } / \%\end{array}$ & $\begin{array}{c}\text { Hundred } \\
\text { bud } \\
\text { weight/g }\end{array}$ & $\begin{array}{c}\text { Growth } \\
\text { rate } \\
\text { compared } \\
\text { with CK } \\
1 \%\end{array}$ & $\begin{array}{c}\text { Fresh tea } \\
\text { output } \\
/\left(\mathrm{kg} / \mathrm{hm}^{2}\right)\end{array}$ & $\begin{array}{c}\text { Compared with } \\
\text { CK increase } \\
\text { production } \\
/\left(\mathrm{kg} / \mathrm{hm}^{2}\right)\end{array}$ & $\begin{array}{c}\text { Yield } \\
\text { growth } \\
\text { rate } / \%\end{array}$ \\
\hline $\mathrm{Q}$ & $80 \mathrm{~b}$ & - & $11.9 \mathrm{a}$ & - & $596 \mathrm{a}$ & - & - \\
$\mathrm{T} 1$ & $100 \mathrm{a}$ & 25.83 & $12.9 \mathrm{a}$ & 8.40 & $632.4 \mathrm{a}$ & 36.41 & 6.11 \\
$\mathrm{~T} 2$ & $84 \mathrm{~b}$ & 3.75 & $12.3 \mathrm{a}$ & 3.36 & $607.8 \mathrm{a}$ & 11.83 & 1.99 \\
$\mathrm{~T} 3$ & $76 \mathrm{~b}$ & -5.00 & $11.7 \mathrm{a}$ & -1.68 & $570.9 \mathrm{a}$ & -25.10 & -4.21 \\
$\mathrm{~T} 4$ & $70 \mathrm{c}$ & -12.50 & $11.6 \mathrm{a}$ & -2.52 & $514.0 \mathrm{bc}$ & -82.00 & -13.76 \\
$\mathrm{~T} 5$ & 64cd & -20.00 & $10.9 \mathrm{a}$ & -8.40 & $460 \mathrm{~cd}$ & -136.02 & -22.82 \\
\hline
\end{tabular}

Lowercase letters indicate significant differences, and the same letters indicate insignificant differences.

Table 3. Effects of different Fertilization treatment on new shoots.

\begin{tabular}{lccc}
\hline Treatment & N content $/ \%$ & P content $/ \%$ & K content $/ \%$ \\
\hline CK & $1.023 \mathrm{a}$ & $0.093 \mathrm{c}$ & $1.653 \mathrm{~b}$ \\
$\mathrm{~T} 1$ & $1.070 \mathrm{a}$ & $0.183 \mathrm{a}$ & $2.237 \mathrm{a}$ \\
$\mathrm{T} 2$ & $1.027 \mathrm{a}$ & $0.153 \mathrm{~b}$ & $1.850 \mathrm{~b}$ \\
$\mathrm{~T} 3$ & $0.640 \mathrm{~b}$ & $0.067 \mathrm{c}$ & $1.690 \mathrm{~b}$ \\
$\mathrm{~T} 4$ & $0.563 \mathrm{~b}$ & $0.053 \mathrm{~cd}$ & $1.433 \mathrm{~b}$ \\
$\mathrm{~T} 5$ & $0.623 \mathrm{~b}$ & $0.047 \mathrm{de}$ & $1.380 \mathrm{~b}$ \\
\hline
\end{tabular}

The same lowercase letters in the same column indicate significant differences, and the same letters indicate insignificant differences.

Chlorophyll is closely related to nitrogen, and nitrogen deficiency will affect the biosynthesis of chlorophyll or cause its decomposition, thereby reducing the chlorophyll content (Guo et al. 2006). The SPAD value determines the chlorophyll content by the difference between the light absorption of the two wavelengths by the leaves, and the measurement result is a relative value reflecting the chlorophyll content in the leaves of the plant (Zhou et al. 2012). The overall SPAD value decreases with the decrease of nitrogen application rate, which was also consistent with the trend of tea production (Fig. 1). It showed that the SPAD value of mature leaves can better characterize the nitrogen nutrient level of tea plants; it also has a relatively obvious relationship with tea plant yield, which shows that SPAD value can be used as a method for diagnosing the lack of nitrogen nutrition in tea plants.

It is apparent from Table 4 that the output values of $\mathrm{T} 1$ and $\mathrm{T} 2$ were all higher than those of $\mathrm{CK}$, and the output values of T3, T4, and T5 were all lower than CK, and the output value of T6 was lower than that of CK. Compared with CK, the fertilization cost of special fertilizer for tea plant was 0.10 4200 yuan $/ \mathrm{hm}^{2}$, which was lower than the input cost of CK fertilizer. Compared with CK treatment, the net income of $\mathrm{T} 1$ and $\mathrm{T} 2$ treatment increased by 6.44 and $2.35 \%$ respectively. The net income of $\mathrm{T} 3, \mathrm{~T} 4$, and $\mathrm{T} 5$ was lower than that of $\mathrm{CK}$ treatment. It can be seen that the application of special fertilizer for tea trees in tea gardens can reduce the cost of 
fertilization and increase the income of tea farmers. Among them, the T2 treatment has a certain income increase effect compared with the CK treatment under the treatment of reducing nitrogen by $20 \%$.

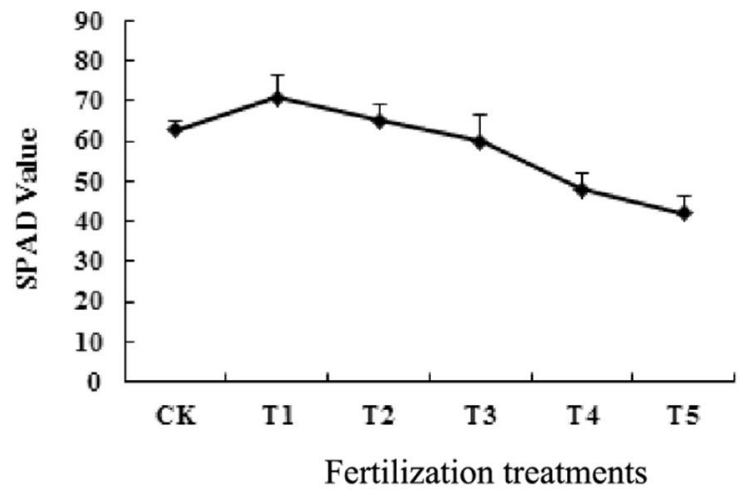

Fig. 1. Effects of different fertilization treatments on SPAD value of mature leaves.

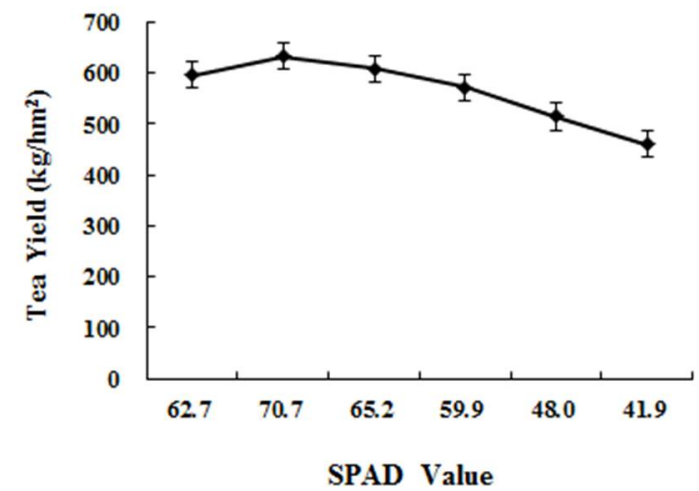

Fig. 2. The relationship between SPAD reading of mature leaves and the tea yield.

\section{Table 4. Economic benefit analysis of fertilization.}

\begin{tabular}{lllll}
\hline Treatment & $\begin{array}{l}\text { Fresh tea production } \\
\left.\text { value/(yuan } \mathrm{hm}^{-2}\right)\end{array}$ & $\begin{array}{l}\text { Compared with CK } \\
\pm \text { output value/ } \\
\left(\mathrm{yuan} \cdot \mathrm{hm}^{-2}\right)\end{array}$ & $\begin{array}{l}\text { Fertilization cost/ } \\
\left(\mathrm{yuan} / \mathrm{hm}^{2}\right)\end{array}$ & $\begin{array}{l}\text { Net income/ } \\
\left(\mathrm{yuan} / \mathrm{hm}^{2}\right)\end{array}$ \\
\hline CK & $11.92 \times 10^{4}$ & - & $0.43 \times 10^{4}$ & $11.49 \times 10^{4}$ \\
T1 & $12.65 \times 10^{4}$ & $0.73 \times 10^{4}$ & $0.42 \times 10^{4}$ & $12.23 \times 10^{4}$ \\
T2 & $12.16 \times 10^{4}$ & $0.24 \times 10^{4}$ & $0.39 \times 10^{4}$ & $11.76 \times 10^{4}$ \\
T3 & $11.42 \times 10^{4}$ & $-0.50 \times 10^{4}$ & $0.31 \times 10^{4}$ & $11.11 \times 10^{4}$ \\
T4 & $10.28 \times 10^{4}$ & $-1.64 \times 10^{4}$ & $0.23 \times 10^{4}$ & $10.05 \times 10^{4}$ \\
T5 & $9.20 \times 10^{4}$ & $-2.72 \times 10^{4}$ & $0.10 \times 10^{4}$ & $9.10 \times 10^{4}$ \\
\hline
\end{tabular}


Tea tree is a kind of leaf plant, and a reasonable combination of organic and inorganic fertilizers based on nitrogen can effectively promote the improvement of tea yield and quality ( $\mathrm{Li}$ et al. 2009). Wang et al. (2018) showed that the application of biomass charcoal can significantly enhance the nitrogen adsorption capacity of the tea garden soil, reduce nutrient leakage and leaching, thereby increasing the yield and quality of tea. In the present experiment, $20 \%$ of the special fertilizer for tea plants and the combined application of quantitative organic fertilizers were reduced, and the germination density, 100-bud weight and fresh tea yield of tea increased slightly, the increase was $3.75,3.36$ and $1.99 \%$, but it did not reach a significant level. The difference indicates that a reasonable nutrient supply is in line with the characteristics of tea plant growth. At the same time, the application of a certain amount of organic fertilizer improved the soil and fertilization, and increased the utilization rate of fertilizer. Compared with the control, the plant nutrient content was not significant. Both the phosphorus and potassium content of the plants showed significant differences. This may be because the application of organic fertilizers reduces the soil's fixation of phosphorus and improves the effective use of phosphate fertilizers. Similarly, the application of organic fertilizers also increases the effective potassium content in the soil and improves the potassium supply capacity. The fertilization costs of T1, T2, T2, T3, and T4 in the present study were all lower than CK treatment, but the benefits of $\mathrm{T} 1, \mathrm{~T} 2$ are significantly higher than conventional treatments, and the benefits of T2, T3, T4 are lower than conventional treatments. The present research results showed that compared with conventional fertilizers, special fertilizers for tea combined with organic fertilizers have the advantage of reducing fertilization and increasing efficiency.

In the present study, the experiment of substituting special fertilizers with organic fertilizers can achieve the goals of promoting tea plant growth, increasing tea production and improving tea quality. It can effectively solve the problem of large total nitrogen fertilizer usage in Xinyang tea gardens, single types of fertilizers, the demand for trace elements and the supply of trace elements in the soil. However, due to the short duration of this experiment, there are certain limitations to draw any conclusion. In the future, more systematic and comprehensive research is needed, such as to study the ratio of organic-inorganic application, to conduct in-depth research on the improvement of the physical properties of the tea garden soil and the influence of the microbial community by the organic alternative model to further clarify the effect of reducing the application of special fertilizers in the tea garden.

\section{Acknowledgements}

This work was financially supported by Shaanxi Provincial Land Engineering Construction Group fund (DJNY-2021-7, DJNY-2021-15).

\section{References}

Bao S 2000. Soil and Agricultural Chemistry Analysis. Beijing: China Agriculture Press, China.

Bora K, Sarkar D, Konwar K, Payeng B, Sood K, Paul RK, Datta R, Das S, Khare P and Karak T 2019. Disentanglement of the secrets of aluminium in acidophilic tea plant (Camellia sinensis L.) influenced by organic and inorganic amendments. Food Res. Int. 120: 851-864.

Costa WD, Mohotti AJ and Wijeratne MA 2007. Ecophysiology of tea. Braz. J. Plant Physiol. 19(4): 299-332.

Gu S, Hu Q, Cheng Y, Bai L, Liu Z, Xiao W, Gong Z, Wu T, Feng K, Deng Y and Tan L 2019. Application of organic fertilizer improves microbial community diversity and alters microbial network structure in tea (Camellia sinensis) plantation soils. Soil Tillage Res. 195: 104356.

Guo GY, Hu KF and Yuan D 2006. Study on chemical composition of maojian tea in Xinyang. Sci Technol. Food. Ind. 12: 162-165. 
Hong X, Zhang L, Zhu Y, Guo X, Jiang O, Liu M, Zhou X and Xu F 2018. Yields and nitrogen use efficiencies of rice (Oryza sativa) at different sites using different nitrogen fertilizer application rates and controlled-release urea to conventional urea ratios. Agric. Biotechnol. 7(3): 149-157+206

Ji L, Wu Z, You Z, Yi X, Ni K, Guo S and Ruan J 2018. Effects of organic substitution for synthetic N fertilizer on soil bacterial diversity and community composition: A 10-year field trial in a tea plantation. Agric. Ecosyst. Environ. 268:124-132.

Li FR, Zhou Q, Shi ZX and Wang C 2009. Relationship between the community composition of rhizosphere microflora and quality of Maojian tea in Xinyang. J. Anhui. Agr. Sci. 37(22): 10489-10491.

Maghanga JK, Kituyi JL, Kisinyo PO and Ng'etich WK 2013. Impact of nitrogen fertilizer applications on surface water nitrate levels within a Kenyan Tea Plantation. J. Chem. 9: 1-4.

Maltas A, Charles R, Jeangros B and Sinaj S 2013. Effect of organic fertilizers and reduced-tillage on soil properties, crop nitrogen response and crop yield: Results of a 12-year experiment in Changins, Switzerland. Soil Tillage Res. 126: 11-18.

Ruan JY, Ma LF, Shi YZ and Zhang F 2004. Effects of litter incorporation and nitrogen fertilization on the contents of extractable aluminium in the-rhizosphere soil of tea plant (Camallia sinensis (L.) O. Kuntze). Plant Soil. 263(1-2): 283-296.

Shen Y, Yang X and Xie X 1990. Effects of late-autumn fertilizer dressing on accumulation of photosynthates in tea (Camellia sinensis) and its contribution to spring tea quality. J. Agric. Sci. 115(2): 233-238.

Sun R, Dsouza M, Gilbert J A, Guo X, Wang D, Guo Z, Ni Y and Chu H 2016. Fungal community composition in soils subjected to long-term chemical fertilization is most influenced by the type of organic matter. Environ. Microbiol. 18(12): 5137-5150.

Sun X, Jin H and Qiao Y 2009. Measurements of multi-angle polarization properties of the water-bearing yellow brown soil using multi-band polarimetric imagery in the laboratory. Proceedings of SPIE-The Int. Soc. Opt. Eng. 7160.

Wang F, Wu ZD, Chen YZ, Jiang F, Zhu L, Zhang W, Weng B and You Z 2018. Effects of the combined application of biochar and nitrogen on growth and nitrogen use efficiency of tea plants. J. Tea. Sci. 38(4): 331-341.

Xie S, Yang F, Feng H, Yu Z and Liang T 2020. Organic fertilizer reduced carbon and nitrogen in runoff and buffered soil acidification in tea plantations: Evidence in nutrient contents and isotope fractionations. Sci. Total Environ. 762(9): 143059.

Yatoo AM, Ali MN, Baba ZA and Hassan B 2021. Sustainable management of diseases and pests in crops by vermicompost and vermicompost tea. A review. Agron. Sustain. Dev. 41(1): 7.

Zhang S, Sun L, Wang Y, Fan K, Xu Q, Li Y, Ma Q, Wang J, Rem W and Ding Z 2020. Cow manure application effectively regulates the soil bacterial community in tea plantation. BMC Microbiol. 20(1), 190.

Zhou XS, Zhou YQ, Pang L, Jiang C and Li Y 2012. Estimate of leaf chlorophyll and nitrogen content in Camellia sinensis by CCM-200. J. Anhui Agr. Univ. 39(1): 150-153.

Zwa B, Yg A and Tao LA 2019. Optimization of reduced chemical fertilizer use in tea gardens based on the assessment of related environmental and economic benefits. Sci. Total Environ. 713: 136439.

(Manuscript received on 15 July, 2021; revised on 27 September, 2021) 